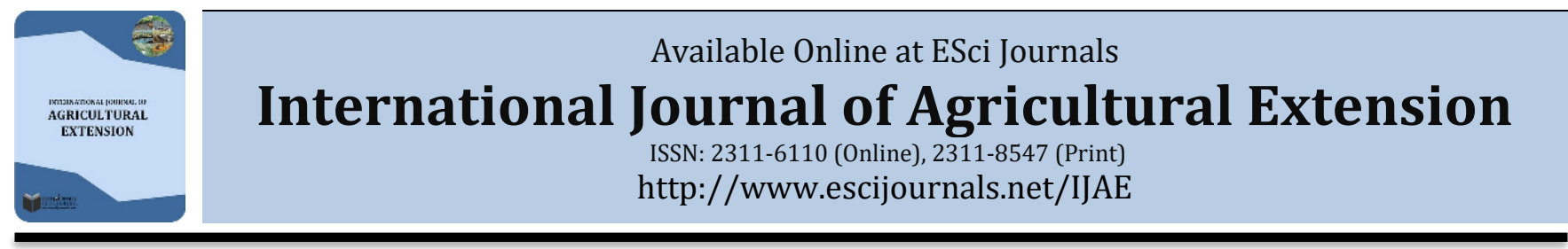

\title{
CONTRIBUTION OF EXOTIC CHICKEN BREEDS TO DIETARY DIVERSITY OF THE RURAL HOUSEHOLDS IN ETHIOPIA
}

\author{
Teklemariam Abadi
}

Shire-Maytsebri Agricultural Research Center, Agricultural Extension Researcher, Shire- Endaslassie, Ethiopia.

\section{A B S T R A C T}

The study was conducted in midland and lowland agro-ecological zone of North western zone of Tigray, Ethiopia. Two districts were selected purposively based on their potential exotic chicken breed production. Out of the total chicken producers in the study area 264 farmers, 132 from each of the two districts were selected randomly using systematic random sampling methods. It was conducted in cross sectional survey data from 264 respondents in 2016. Its aim was to assess the contribution of producing exotic chicken to dietary diversity of the rural households with 24 hours recall method. The study examines the study area is characterized in a low dietary diversity mainly defined by starchy staples (grains, condiments, oil or fats) at the expense of protein sources (meat, fish, fruits, vegetables, eggs). The result also indicates that there is a higher probability of the exotic chicken producers' groups to move from a medium dietary diversity status to a high dietary diversity status as compared with indigenous chicken producers. Based on the study result, there is possibility to improve dietary diversity and income of the households through introduction and dissemination of exotic chicken breeds to rural households. Hence, governmental and non-governmental organizations should help in intervention of exotic chicken breed to the farm households by giving different incentives.

Keywords: Dietary diversity score, food groups, 24 hours recall.

\section{INTRODUCTION}

Dietary diversity can be defined as the number of different foods or food groups consumed by humans over a given reference period (FAO, 2007). Based on the assumption that no single food can contain all nutrients; dietary diversity has been conjectured to have a greater practical potential of meeting nutrient requirements (Labadarios et al., 2011). This could be an indicator of nutrient adequacy (Kennedy, 2009). Increase in dietary diversity is associated with socioeconomic status and household energy availability (Hoddinot \& Yohannes, 2002). Dietary diversity is usually measured by summing the number of foods or food groups consumed over a reference period (Vakili et al., 2013). Dietary diversity scores and percent households consuming each food group can be used as a one-time measure (Gina et al., 2010). The reference period usually ranges from one

* Corresponding Author:

Email: teklish190@gmail.com

(C) 2018 ESci Journals Publishing. All rights reserved. to three days, but seven days is also often used (FAO, 2011), and periods of up to 15 days have been reported (Ruel, 2002). The rationale for emphasizing dietary diversity in developing countries rooted mainly from a concern related to nutrient deficiency and the recognition of the importance of increasing food and food group variety to ensure nutrient adequacy. Lack of dietary diversity is a particularly severe problem among poor populations in the developing world, because their diets are predominantly based on starchy staples and often include little or no animal products and few fresh fruits and vegetables (Ruel, 2002).

Chicken is one of the few alternative animal protein sources for the resource poor farmers. Meat and egg of a chicken are the best source of quality protein and is critically needed and demanded by many clients. A typical egg contains about $65 \%$ moisture, $12 \%$ protein, $11 \%$ ash, $11 \%$ fat and $1 \%$ of carbohydrates (Evbuomwan, 2005). This protein is very rich in essential amino acids, which are highly desirable in the 
diets of humans and this played a significant role in family nutrition, especially for young children to grow strong and healthy and thus have greater role in reducing malnutrition.

Both chicken meat and egg enrich and contribute to a well-balanced diet to satisfy human needs. An average adult human needs about 65g of protein per a day, of which only $10 \%$ needs to be protein of animal origin (Tadelle et al., 2003). Approximately $20 \%$ of the protein consumed in developing countries gained from poultry (Askov \& Dolberg, 2002). Peoples can acquire protein and diversify their diet by eating chicken meat and egg. Because egg and meat of chicken are two types of food among the 12 food groups that used for measuring dietary diversity (FAO, 2007). Chickens and chicken products such as meat and eggs are important foods for improving nutritional and health status, particularly for risk populations, like children, pregnant women and debilitated persons (Olaniyi et al., 2008). Tigray region owns about 6.2 million chickens (CSA, 2015). The study area, north western zone of Tigray, is one of the major chickens producing zones in the Region, which accounts for about 38\% chicken population of the Tigray region (CSA, 2015). To enhance production and productivity of chicken different efforts such as introduction and dissemination of exotic chickens to farmers had been conducted in the study area. As farmers own exotic chicken breeds they could produce more egg and chicken meat than indigenous chicken producers. Ultimately, chicken can play a vital role to household food diversity and nutrition security. However, there is no any study executed regarding contribution of exotic chicken to dietary diversity of the farm households in the study area. Therefore, the purpose of this study is to assess the contribution of exotic chicken breeds to dietary diversity of the household as compared with the indigenous chicken producers.

\section{MATERIALS AND METHODS}

Description of the Study Area: The study was conducted in North western zone of Tigray, Northern Ethiopia. Tahtaykoraro from midland and Tselemti from lowland agro-ecologies, were purposively selected based on their exotic chicken breeds production potentiality. Tselemti district is found $1172 \mathrm{~km}$ from Addis Ababa, $389 \mathrm{~km}$ west of Mekelle and $85 \mathrm{~km}$ south of Shire; while, Tahtaykoraro district is located $1087 \mathrm{~km}$ from Addis Ababa and $304 \mathrm{~km}$ west of Mekelle.

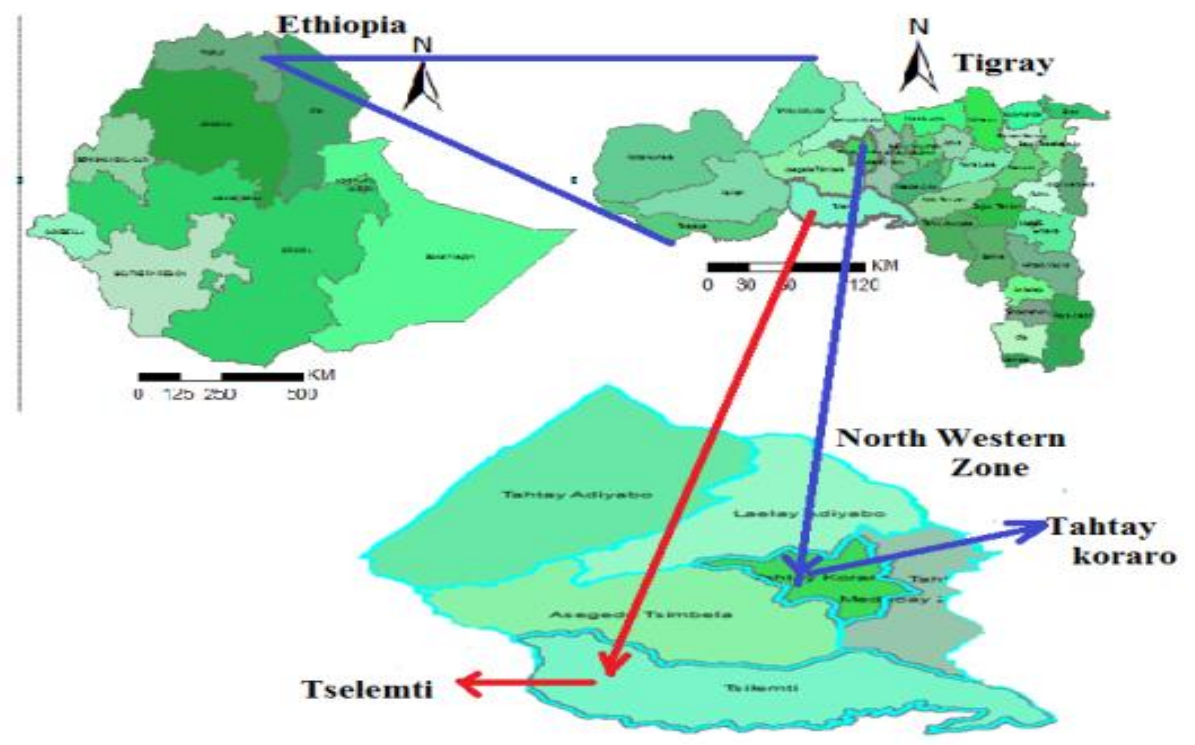

Figure1. Map of the study area.

Sampling Procedures: Multi-stage sampling procedure was employed to select respondent households. On first stage, Tselemti and Tahtaykoraro districts were selected purposively based on their potential exotic chicken breed production from north western zone of Tigray. On second stage, among the identified Kebelles, three Kebelles from each of the two districts was selected using simple random sampling technique. The farmers 
were selected purposively that produce chickens. The number of sample respondents from each of the selected Kebelles, exotic chicken users and indigenous chicken users were identified based on the probability proportionate to sample size in each of the selected Woredas.

Then, respondents were selected using systematic random sampling from both strata (exotic chicken users and indigenous chicken users). Finally, 132, farm households from each of the two districts a total of 264 sample households were selected for the study. Exotic chicken users are those producers who are involved in exotic chicken production either in pure or cross breed forms during the survey year; whereas, indigenous chicken users are those producers of chicken who have not kept exotic chicken before.

Table 1. The number of households selected from each Kebelles.

\begin{tabular}{|c|c|c|c|c|c|c|c|c|}
\hline \multirow[t]{2}{*}{ No. } & \multirow[t]{2}{*}{ District } & \multirow[t]{2}{*}{ Kebelle } & \multicolumn{3}{|c|}{$\begin{array}{l}\text { Total Number of } \\
\text { Households in the } \\
\text { Sampled Kebelles }\end{array}$} & \multicolumn{3}{|c|}{$\begin{array}{l}\text { Sample households } \\
\text { Selected }\end{array}$} \\
\hline & & & $\begin{array}{l}\text { Indigenous } \\
\text { chicken } \\
\text { producers }\end{array}$ & $\begin{array}{l}\text { Exotic chicken } \\
\text { producers }\end{array}$ & Total & $\begin{array}{l}\text { Exotic } \\
\text { chicken } \\
\text { producers }\end{array}$ & $\begin{array}{l}\text { Indigenous } \\
\text { chicken } \\
\text { producers }\end{array}$ & Total \\
\hline \multirow[t]{4}{*}{1} & Tselemti & Wuhdet & 550 & 830 & 1380 & 21 & 31 & 52 \\
\hline & & Medhanalem & 625 & 739 & 1364 & 23 & 28 & 51 \\
\hline & & Mai-ayni & 324 & 452 & 776 & 12 & 17 & 29 \\
\hline & & Sub total & 1499 & 2051 & 3520 & 56 & 76 & 132 \\
\hline \multirow[t]{5}{*}{2} & Tahtaykoraro & Selam & 458 & 687 & 1145 & 18 & 26 & 44 \\
\hline & & Adigdad & 550 & 790 & 1340 & 21 & 30 & 51 \\
\hline & & Haftom & 387 & 578 & 965 & 15 & 22 & 37 \\
\hline & & Sub total & 1395 & 2055 & 3450 & 54 & 78 & 154 \\
\hline & & Grand total & 2894 & 4076 & 6970 & 110 & 154 & 264 \\
\hline
\end{tabular}

Source: Office of Agriculture and Rural Development, 2016.

Data sources and Methods of Data Collection: Both primary and secondary data were collected and used for this study. Primary data was collected from sample respondents through interviewing using semistructured questionnaire. The survey was conducted from October-December 2016 through hiring enumerators. The hired enumerators are those who have experience in conducting farm household surveys and familiar with the study areas. All the enumerators were having at least with Diploma. Enumerators were trained regarding the contents of the questionnaire and data collection procedure. Trained enumerators interviewed the sample respondents under a close and continuous supervision of the researcher. Secondary data were collected from different relevant sources such as reports of Woreda Office of Agriculture and Rural Development, Central Statistical Agency, Research Center, different published and unpublished documents, research studies, websites, etc.
A scale of twelve food groups was used to assess the dietary diversity of respondents at household level. Food items belonging to different food groups that could be prepared and consumed at home or outside home, purchased or gathered from outside were considered for this study. Following the FAO (2007) guideline, the dietary diversity scores of respondents were estimated using information collected from the 24-hours dietary recall from the respondents' food intake. The respondents were asked to recall all foods eaten and beverages taken in the previous twenty-four hours before to the interview day. A scale of twelve food groups was used in assessing the dietary diversity of the respondents as summarized in table 2. A single point was given to each of the food groups consumed over the reference period giving a maximum sum total dietary diversity score of 12 points for each individual in the event that his/her responses are positive to all food groups. 
Table2. Categories of food groups.

\begin{tabular}{clc}
\hline Sr. & Food groups & Scores \\
\hline 1 & Any food from grain, biscuit & 1 \\
2 & Any legumes & 1 \\
3 & Any food from tuber or root & 1 \\
4 & Any vegetables & 1 \\
5 & Any fruits & 1 \\
6 & Any meats & 1 \\
7 & Eggs & 1 \\
8 & Fish & 1 \\
9 & Milk products excluding butter & 1 \\
10 & Foods made from oil & 1 \\
11 & Sugar or honey & 1 \\
12 & Other foods such as spices, condiments, coffee or tea, beverages & 1 \\
\hline
\end{tabular}

Keys: if the answer is "Yes" give 1point; If the answer is "No" give 0 point.

Data analysis: The dietary diversity was analyzed using of the food group types between exotic chicken and descriptive statistics such as percentage and mean. indigenous chicken users. SPSS (Statistical package for Besides, t-test was also used to see the mean difference Social Sciences) software used for analyzing the data.

Table 3. Socio-economic and demographic characteristics of the respondents

\begin{tabular}{|c|c|c|c|c|c|c|c|}
\hline \multirow[t]{2}{*}{ No } & \multirow[t]{2}{*}{ Continuous Variables } & & \multicolumn{2}{|c|}{$\begin{array}{l}\text { Exotic chicken producers } \\
n=110\end{array}$} & \multicolumn{2}{|c|}{ Indigenous chicken producers } & \multirow[t]{2}{*}{ t-value } \\
\hline & & & \multicolumn{2}{|c|}{ Mean (SD) } & \multicolumn{2}{|c|}{ Mean (SD) } & \\
\hline 1 & Age (year) & Age (year) & \multicolumn{2}{|c|}{$41.28(8.78)$} & \multicolumn{2}{|c|}{$47.64(7.87)$} & $7.32^{* * *}$ \\
\hline 2 & Family size (number) & & \multicolumn{2}{|c|}{$6.51(1.12)$} & \multicolumn{2}{|c|}{$4.50(0.94)$} & $2.57^{* * *}$ \\
\hline 3 & \multicolumn{2}{|l|}{ Experience (year) } & \multicolumn{2}{|c|}{$11.68(7.80)$} & \multicolumn{2}{|c|}{$13.89(8.74)$} & $2.30 \mathrm{NS}$ \\
\hline 4 & \multicolumn{2}{|l|}{ Livestock holding (TLU) } & \multicolumn{2}{|c|}{$4.30(3.92)$} & \multicolumn{2}{|c|}{$7.82(4.69)$} & $6.69^{* * *}$ \\
\hline \multirow[t]{3}{*}{5} & \multicolumn{2}{|l|}{ Market distance $(\mathrm{km})$} & \multicolumn{2}{|c|}{$7.29(15.68)$} & \multicolumn{2}{|c|}{$9.22(25.09)$} & $10.86^{* * *}$ \\
\hline & \multirow[t]{2}{*}{ Dummy Variables } & \multirow[b]{2}{*}{ Description } & \multicolumn{2}{|c|}{ Exotic chicken producers } & \multicolumn{2}{|c|}{ Indigenous chicken producers } & \\
\hline & & & $\mathrm{n}$ & $\%$ & $\mathrm{n}$ & $\%$ & $\chi 2$ value \\
\hline \multirow[t]{2}{*}{6} & \multirow[t]{2}{*}{ Sex } & Male & 93 & 84.55 & 130 & 84.4 & $11.3^{*}$ \\
\hline & & Female & 17 & 15.45 & 24 & 15.6 & \\
\hline \multirow[t]{2}{*}{7} & \multirow[t]{2}{*}{ Education status } & Literate & 98 & 89.1 & 58 & 37.7 & $70.21^{* * *}$ \\
\hline & & Illiterate & 12 & 10.9 & 96 & 62.3 & \\
\hline \multirow[t]{2}{*}{8} & \multirow[t]{2}{*}{ Off farm income } & Yes & 69 & 62.7 & 37 & 24 & $39.99^{* * *}$ \\
\hline & & No & 41 & 37.3 & 117 & 76 & \\
\hline \multirow[t]{2}{*}{9} & Access to breed & Yes & 93 & 84.5 & 101 & 65.6 & $11.84^{* * *}$ \\
\hline & & No & 17 & 15.5 & 53 & 34.4 & \\
\hline 10 & Credit access & Yes & 81 & 73.6 & 96 & 62.3 & $39.30^{* * *}$ \\
\hline & & No & 29 & 26.4 & 58 & 37.7 & \\
\hline 11 & Extension contact & Yes & 103 & 93.6 & 91 & 59.1 & $76.43^{* * *}$ \\
\hline & & No & 7 & 6.4 & 63 & 40.9 & \\
\hline 12 & Training & Yes & 82 & 74.5 & 4 & 2.6 & $16.93^{* * *}$ \\
\hline & & No & 28 & 25.5 & 150 & 97.4 & \\
\hline 13 & Vaccination access & Yes & 4 & 3.6 & 12 & 7.8 & $1.49 \mathrm{NS}$ \\
\hline & & No & 106 & 96.4 & 142 & 92.2 & \\
\hline
\end{tabular}

*** and ${ }^{*}$ significant at $1 \%$ and $10 \%$ level of significance, respectively, NS =Not Significant, SD =Standard Deviations. 


\section{RESULTS AND DISCUSSION}

\section{Socio-economic attributes of the respondents}

Age of the Household head: The mean age of the respondents is 44.46 years. The average age of exotic chicken producer and indigenous chicken producers were 41.28 and 47.64 , respectively. The t-test analysis result shows that, age had a significant mean difference between exotic chicken producer and indigenous chicken producers' categories at $1 \%$ level of significance. Sex of the Household head: The result of the survey indicates that out of the total sample household heads $84.55 \%$ and $84.4 \%$ are male headed households, respectively, exotic chicken producer and indigenous chicken producers. The variable household sex was shown a significant difference between exotic chicken producer and indigenous chicken producers at $10 \%$ level of significance. Male headed households tend to produce exotic chicken than producing indigenous chickens.

Education status of the Households head: Among the sample households, $40.9 \%$ were illiterate and 59.1\% were literate. The result of chi-square-test revealed that there is a significant relationship between education status and exotic chicken breeds producers at $1 \%$ level of significance. As the farmer become more educated tend to use exotic chicken breeds.

Family size of the Households: Family size was shown a significant difference between exotic chicken producers and indigenous chicken producers at $1 \%$ significance level. The average family size for exotic chicken producer and indigenous chicken producers were 6.5 and 4.5 persons, respectively. As the household have large family size, becomes more user of exotic chicken and improve their dietary diversity.

Livestock holding: To describe the livestock holding of the sample households the Tropical Livestock Unit (TLU) conversion factor was used following (Storck et al., 1991). The average livestock holding in TLU of the exotic chicken producer and indigenous chicken producers sample households was 4.3 and 7.82 TLU, respectively (Table 3). The livestock holding in TLU shows that there is statistically significant difference between exotic chicken producers and indigenous chicken producers.

Off-farm Income Activities: The off-farm participation difference between exotic chicken producer and indigenous chicken producers were found to be significant at $1 \%$ probability level.

Access to credit service: Credit is important to overcome the financial constraints and plays a vital role in using the new technologies which helps for households to purchase inputs for agricultural production. The proportion difference between exotic chicken producer and indigenous chicken producers in access to credit was found to be significant $1 \%$ level of significance.

Market distance: The households located near to market tend to buy improved agricultural inputs such as breed, and they can have easy access to sell their product in the market. The sample households on average travelled about $8.25 \mathrm{~km}$ to sell their chicken products. The average distance taken for the household to travel from the residence to the nearest market place is 7.29 and $9.22 \mathrm{~km}$, respectively, for exotic chicken producer and indigenous chicken producers.

Extension contact: Receiving extension services from extension agent make for farmers to have the knowhow and information access to new technologies. Among the exotic chicken producers, $93.6 \%$ had contact with extension agents, whereas, $59.1 \%$ of the indigenous chicken producers had the same.

Participation in training: Participating farmers in training help farmers to equip with new knowledge and skill, which enables them to perform new practice properly. The proportion difference between exotic chicken producer and indigenous chicken producers in access to training was found to be significant $1 \%$ level of significance.

Access to exotic chicken breeds: As the farmer is more accessible for exotic chicken breed, the better is the decision of using exotic chicken breeds. The chi-square result revealed that, access to exotic chicken breeds had statistically significant relationship with the adoption of exotic chicken breeds at1\% significance level.

Rural household food groups and beverages: Of the total 264 sample respondents $41.7 \%$ of them were involving in exotic chicken production; while the remaining $58.3 \%$ farmers were rearing local chicken. According to FAO (2006) dietary diversity that derived from the 12 food groups are categorized into; low, medium and high dietary diversity groups as summarized in Table 4. Categorization of respondents with respect to dietary diversity a majority were classified in the medium dietary diversity category; which is $59.1 \%$ of exotic chicken producers and $43.5 \%$ of indigenous chicken producers. However, in high dietary diversity category only $17.3 \%$ of exotic chicken producers and $2.6 \%$ of indigenous chicken producers were categorized. This indicates that exotic chicken producers 
were getting better dietary diversity than indigenous chicken producers.

Types of food items: Data attributed in Table 5 focuses on reported food groups and beverages from the study area based on a 24 hour dietary recall. The distribution indicates that the following food groups were common: foods from grain (100\%); food from spices and condiments $(100 \%)$, foods containing oil or fat $(68.9 \%)$, foods from legumes (37.8\%) and eggs $(22.3 \%)$. The following food groups were also reported but not commonly shared in the study area: vegetables (14.4\%), root and tuber $(12.1 \%)$, milk $(11.7 \%)$, honey or sugar (8.3\%) meats (4.5\%), fruits $(10.6 \%)$ and fish $(0.76 \%)$. From the observed distribution it indicates that, rural households' diets are mainly dominated by food groups rich in condiments, oils, grains and legumes, but have low food groups of milk, root and tuber, meats, eggs, fish, fruits and vegetables. This may imply a low dietary diversity for the rural poor communities mainly defined by starchy staples. However, introducing exotic chicken breeds could play significant role in improving dietary diversity among rural households. For instance, as indicated in Table 5 results, $34.5 \%$ of exotic chicken producers and $13.6 \%$ of indigenous chicken producers were consumed egg in the day before the survey period. This indicates that a larger number of exotic chicken producers were consuming eggs than indigenous chicken producers. This implies that, exotic chicken producer has a better probability of diversifying their diet than indigenous chicken producers. This could be either directly by consuming the chicken product or through purchasing other food types using income generated from sale of chickens and its eggs. Findings of Nielsen et al. (2003) and Darudec (2002) had unveiled that producing improved chicken breeds had a direct effect on increasing consumption of eggs and chicken meat as well as an indirect income effect (enhanced income from improved chicken being used to purchase other food items). In line to this, meat and egg of a chicken are the best source of quality protein and are critically needed.

Table 4. Categorization of respondents with respect to dietary diversity.

\begin{tabular}{llccc}
\hline & & $\begin{array}{c}\text { Low Dietary } \\
\text { Diversity }\end{array}$ & $\begin{array}{c}\text { Medium Dietary } \\
\text { Diversity }\end{array}$ & $\begin{array}{c}\text { High Dietary } \\
\text { Diversity }\end{array}$ \\
\hline Dietary Diversity Score & & $0-3$ & $4-6$ & $7-12$ \\
\hline \multirow{2}{*}{ No, of respondents } & Exotic chicken producers & $26(23.6 \%)$ & $65(59.1 \%)$ & $19(17.3 \%)$ \\
& Indigenous chicken producers & $83(53.9 \%)$ & $67(43.5 \%)$ & $4(2.6 \%)$ \\
& Total respondents & $109(41.3 \%)$ & $132(50 \%)$ & $23(8.7 \%)$ \\
\hline
\end{tabular}

Source: Own survey result, 2016.

Table 5. Types of food items from different food groups consumed by sample households by 24 hours recall.

\begin{tabular}{lcccccc}
\hline \multirow{2}{*}{$\begin{array}{l}\text { Types of food group } \\
\text { consumed the day } \\
\text { before survey }\end{array}$} & \multicolumn{2}{c}{ Exotic } & \multicolumn{2}{c}{ Indigenous } & \multicolumn{2}{c}{ Total } \\
& chicken producers & chicken producers & & \\
\cline { 2 - 7 } & Frequency & $\%$ & Frequency & $\%$ & Frequency & $\%$ \\
\hline Any food from grain & 110 & 100 & 154 & 100 & 264 & 100 \\
Any food from legumes & 47 & 42.7 & 53 & 34.4 & 100 & 37.8 \\
Any food from root and tuber & 25 & 22.7 & 7 & 4.5 & 32 & 12.1 \\
Any food from vegetables & 32 & 29.1 & 6 & 43.9 & 38 & 14.4 \\
Any fruit & 13 & 11.8 & 15 & 9.7 & 28 & 10.6 \\
Any meat & 9 & 8.2 & 3 & 1.9 & 12 & 4.5 \\
Egg & 38 & 34.5 & 21 & 13.6 & 59 & 22.3 \\
Fish & 2 & 1.8 & - & - & 2 & 0.76 \\
Milk, cheese, yogurt & 12 & 10.9 & 19 & 12.3 & 31 & 11.7 \\
Honey or sugar & 6 & 5.4 & 16 & 10.4 & 22 & 8.3 \\
Any oil or fat, butter & 90 & 81.8 & 92 & 59.7 & 182 & 68.9 \\
Others (Any spices, condiments, tea, coffee, salt, & 110 & 100 & 154 & 100 & 264 & 100 \\
beverage etc.) & & & & & & \\
\hline
\end{tabular}

Source: Own survey result, 2016. 
The number of food items from different food groups consumed by sample respondents by 24 hours recall method was found to be significantly different for exotic chicken producer and indigenous chicken producers at $5 \%$ level of significance. The numbers of food items from different food groups consumed by exotic chicken producer with 4.49 mean values was slightly higher than that of indigenous chicken producers, 3.51 (Table 6). This could be due to the reason that households rearing exotic chicken breeds generating more income than that of indigenous chicken producers and there by getting a chance to buy different food items easily. Any increase in a given household's dietary diversity reflects an improvement in that household's diet quality.

Table 6. Number of food groups consumed by sample households by 24 hours recall

\begin{tabular}{lcccc}
\hline Parameters & $\begin{array}{c}\text { Exotic chicken } \\
\text { producers }\end{array}$ & $\begin{array}{c}\text { Indigenous chicken } \\
\text { producers }\end{array}$ & t-value & p-value \\
\cline { 2 - 4 } & $\mathrm{n}=110$ & $\mathrm{n}=154$ & & $0.042^{* *}$ \\
\hline $\begin{array}{l}\text { Number of food groups consumed in one day } \\
\text { before the survey period }\end{array}$ & 4.49 & 3.51 & 7.45 & \\
\hline
\end{tabular}

Source: Own survey result, 2016.

\section{CONCLUSIONS AND RECOMMENDATIONS}

The result of this study inferred that there is a positive association between ownership of exotic chicken and high dietary diversity. This indicates that an exotic chicken producers group enables to move from a medium dietary diversity status to a high dietary diversity status than indigenous chicken producers. As the household produces exotic chicken breeds the household could obtain more eggs and chicken meat and have better dietary diversity as compared to indigenous chicken producers.

The numbers of food items from different food groups consumed by exotic chicken producer with 4.49 mean values was slightly higher than that of indigenous chicken producers, 3.51. As the result highlights, introducing and promotion of exotic chicken breeds to rural households could improve dietary diversity of the households than using the local ones. Therefore, governmental and non-governmental organizations should help in intervention of exotic chicken breed to the farm households by giving different incentives such as training and creating awareness on the purpose exotic chicken to the household's so as to improve dietary diversity and purchasing power (income) of the rural households.

Acknowledgement: The author would like to acknowledge Tigray Agricultural Research Institute for the research grant. Special thanks also go to agricultural experts and respondent farmers of Tselemti and Tahtaykoraro districts for their kind cooperation for the study.

\section{REFERENCES}

Askov, H. \& Dolberg, F. (2002). A Conceptual Framework for Using Poultry as a Tool in Poverty Alleviation. University of Aarhus, Aarhus, Denmark.

CSA (Central Statistical Agency). (2014/15). Agricultural sample survey Vol. II. Statistical Bulletin No. 446.CSA, Addis Ababa, Ethiopia, 2015.

Darudec, (2002). The Bangladesh semi-scavenging poultry model. Study on the impact, structure and function of the poultry model in the Danida funded agricultural sector programme support (ASPS) with special reference to the implementation of the participatory livestock development project. Danida /Ministry of Foreign Affairs.

Evbuomwan, G.O. (2005). Empirical analysis of cost and benefit returns to commercial table egg production in Lagos state.

FAO (Food and Agriculture Organization). (2006). Baseline Survey Report Protecting and Improving Household Food Security and Nutrition in HIV/AIDS Affected Areas in Manica and Sofala Province, Maputo, Mozambique.

FAO (Food and Agriculture Organization). (2007). Guidelines for measuring household and individual dietary diversity, Nutrition and Consumer Protection Division with support from the FAO Food Security Information for Action Program and the Food and Nutrition Technical Assistance (FANTA) Project, Rome, Italy.

FAO (Food and Agriculture Organization). (2011). Guidelines for measuring household and 
individual dietary diversity, Food and Agriculture Organization of the United Nations, Rome, Italy.

Gina, K., Terri, B. \&Marie, C. D. (2010). Guidelines for measuring household and individual dietary diversity. Nutrition and Consumer Protection Division, Food and Agriculture Organization of the United Nations.

Hoddinot, J. \& Yohannes, Y. (2002). Dietary diversity as a food security indicator. FANTA .2002. Washington DC. Am J ClinNutr, 73.

Kennedy, G., Fanou, N., Seghieri, C., \& Brouwer, I.D. (2009). Dietary diversity as a measure of the micronutrient adequacy of women's diets: results from Bamako, Mali site, Food and Nutrition Technical Assistance II Project (FANTA-2).

Labadarios, D., Steyn, N.P. \& Nel, J. (2011). How diverse is the diet of adult? South African, Nutrition Journal, 10 (33).

Nielsen, H., Roos, N. \& Thilsted, S.H. (2003). Animal source foods to improve micronutrient nutrition and human function in developing countries: the impact of semi-scavenging poultry production on the consumption of animal source foods by women and girls in Bangladesh. Journal of Nutrition, 11, 133.

Olaniyi, B. O., Adesiyan, B. A. \& Ayoade, R. A. (2008).
Constraints to utilization of poultry production technology among farmers in Oyo State, Nigeria. Journal of Human Ecology, 24(4), 305-309.

OoARD (Office of Agriculture and Rural Development). (2016). Unpublished Annual Report. Woreda of Tselemti and Tahtaykoraro, Ethiopia.

Ruel, M. T. (2002). Is Dietary Diversity an Indicator of Food Security or Dietary Quality? A Review of Measurement Issues and Research Needs. FCND Discussion Paper No. 140: p. 58. Washinton, DC: International Food Policy Research Institute.

Storck, H., Bezabih Emana, Birhanu Adnew, Borowiecki, A. and Shimeles W/Hawariate. (1991). Farming systems and farm management practices of smallholders in the Hararghe Highlands: Farming systems and resources economics in the tropics. Wissen shaftsvarlagvauk, Kiel, Germany, 11, 4148.

Tadelle D., Nigusie, D., A. Yami \& Peters, K.J. (2003). The feed resource base and its potentials for increased poultry production in Ethiopia. World's Poultry Science Journal, 58(1), 77-87.

Vakili, M., Abedi, P., Sharifi, M. and Hosseini, M. (2013). Dietary Diversity and Its Related Factors among Adolescents: A Survey in Ahvaz-Iran. Global Journal of Health Science, 5(2), 181. 
Int. J. Agr. Ext. 06 (02) 2018. 99-107
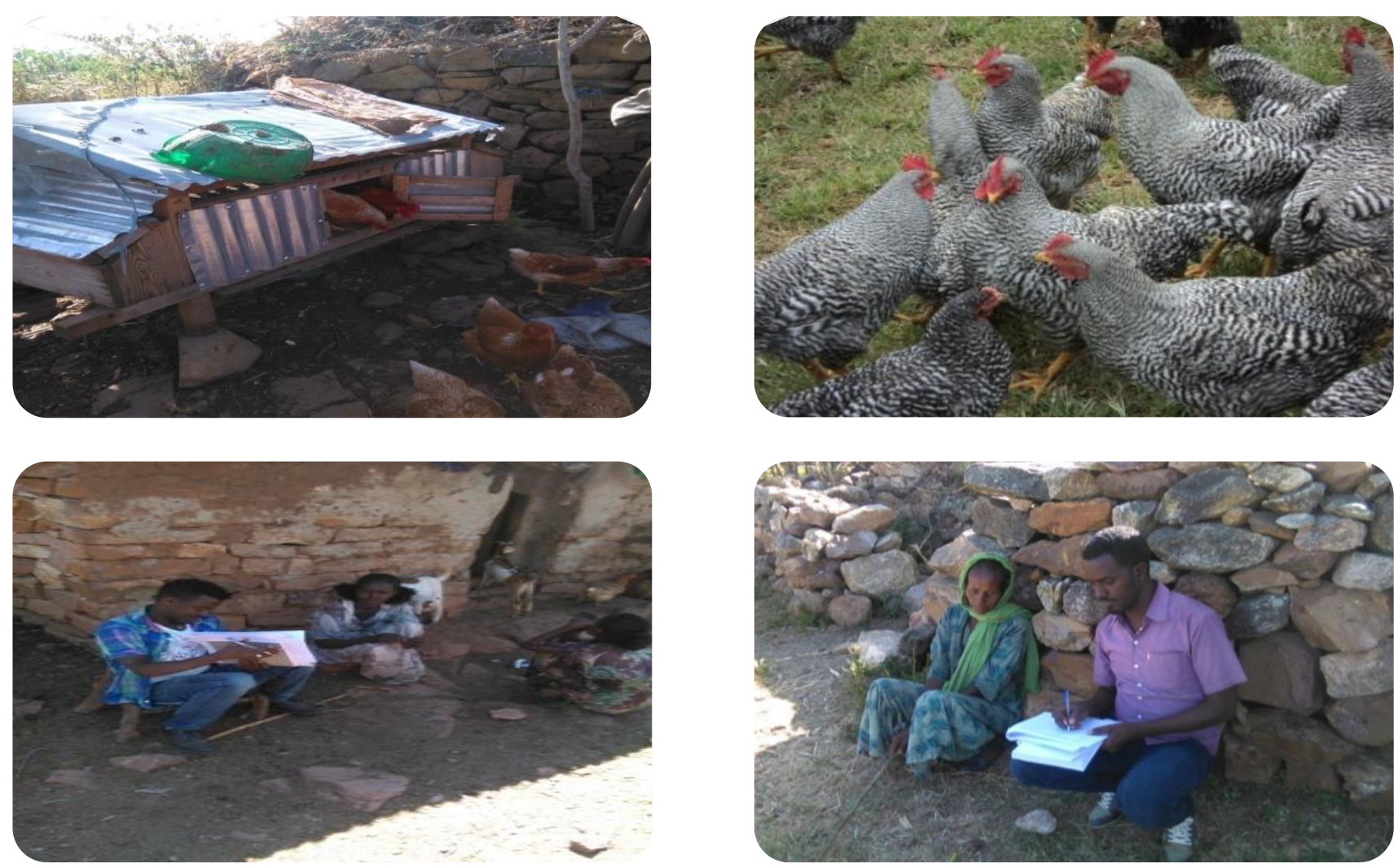

Appendices: Figure1. Types of exotic chicken breed in the study area and data collection method (individual interview). 